\title{
Tradizione e contestazione IV. Le avanguardie: canone $e$ anticanone. Les avant-gardes: canon et anti-canon, a cura di Giovanna Angeli
}

\section{Elena Mazzoleni}

\section{(2) OpenEdition \\ Journals}

Edizione digitale

URL: http://journals.openedition.org/studifrancesi/5746

DOI: $10.4000 /$ studifrancesi. 5746

ISSN: 2421-5856

\section{Editore}

Rosenberg \& Sellier

\section{Edizione cartacea}

Data di pubblicazione: 1 septembre 2011

Paginazione: $450-451$

ISSN: 0039-2944

\section{Notizia bibliografica digitale}

Elena Mazzoleni, «Tradizione e contestazione IV. Le avanguardie: canone e anticanone. Les avant-gardes: canon et anti-canon, a cura di Giovanna Angeli», Studi Francesi [Online], 164 (LV | II) | 2011, online dal 30 novembre 2015, consultato il 11 janvier 2021. URL: http://journals.openedition.org/studifrancesi/5746 ; DOI: https://doi.org/10.4000/studifrancesi.5746

Questo documento è stato generato automaticamente il 11 janvier 2021.

\section{cc) (†) $\odot$}

Studi Francesi è distribuita con Licenza Creative Commons Attribuzione - Non commerciale - Non opere derivate 4.0 Internazionale. 


\title{
Tradizione e contestazione IV. Le avanguardie: canone e anticanone. Les avant-gardes: canon et anti-canon, a cura di Giovanna Angeli
}

\author{
Elena Mazzoleni
}

\section{NOTIZIA}

Tradizione e contestazione IV. Le avanguardie: canone e anticanone. Les avant-gardes: canon et anti-canon, a cura di Giovanna ANGELI, Firenze, Alinea, 2009, 199 pp.

1 Nell'ottobre 2009 si è tenuto un convegno che ha riunito le Università di Firenze, di Padova e di Siena nel comune interesse per lo studio del canone nella letteratura francese dal classicismo alla modernità. Frutto di questo incontro, il volume curato da Giovanna Angeli mette in luce quanto i movimenti d'avanguardia, considerati come i più anticanonici della cultura occidentale, non siano in netta contrapposizione con la tradizione. Nella prima metà del Novecento le avanguardie, con un'azione tanto più efficace quanto più coerente e coesa, promuovono esperimenti che mutano le arti e i mezzi comunicativi.

2 La prima sezione, «Ricognizioni teoriche», illustra la tendenza avanguardista a recuperare e insieme a rifiutare la tradizione letteraria e artistica. Muovendo dalla constatazione che nell'arte occidentale il nudo è sempre stato l'incarnazione della norma, Arnauld PIERRE (Physiologie artistique et rupture du canon esthétique dans l'art autour de 1900, pp. 31-46) ritiene che la fisiologia artistica del corpo in movimento, elaborata da Duchamp e Richer, produca un codice nuovo in opposizione all'ideale estetico. L'intervento di Maria Grazia MESSINA (Il controverso canone della modernità nelle arti visive, pp. 47-55) illustra la nascita del canone della modernità in ambito statunitense. A seguito delle esposizioni degli anni Quaranta al MoMa, le teorizzazioni di Rosalind 
Krauss e Yves-Alain Bois relative al concetto di "informe" sanciscono la fine del canone modernista definendo l'opera d'arte come un'operazione legata alla centralità del corpo nelle sue funzioni percettive. Dato il canone come ciò che è costantemente riattualizzato, Marielle MACÉ (Breton, Queneau, Blanchot et les totalités culturelles. «Tout, et pas seulement tout», pp.56-73) riconosce l'anticanone nella crisi del sistema della memoria e della letteratura intesa come totalità. Le risposte di Blanchot e di Breton al quesito di Queneau a proposito di una biblioteca ideale testimoniano l'atteggiamento avanguardista nei confronti della norma: l'interesse non sta più nella scelta delle opere classiche, quanto nel rapporto tra i lettori e la biblioteca-universo.

Stante l'impossibilità di definire il confine tra canone e anticanone, la seconda parte, «Genealogie surrealiste», pone il fuoco sul surrealismo come esperienza che nega il binomio tradizione-contestazione. Secondo Jacqueline CHÉNIEUX-GENDRON le opere surrealiste non generano degli «anti-canons» (p. 91), bensì dei sistemi teorici che mirano all'assimilazione dei modelli (Canons, codes, modèles et les divers modes de leur contestation dans le surréalisme, pp. 87-102).

4 La parte finale approfondisce la sperimentazione e la violazione dei codici da parte delle avanguardie in ambito teatrale-cinematografico. Alessandro TINTERRI (La scena dei Dioscuri: tra metafisica e surrealismo, pp. 156-168) presenta l'esperienza poliespressiva musicale e teatrale di Savinio. L'unione tra modello e contestazione si articola su sfondi sospesi tra metafisica e realtà, contaminazione dei generi e rivisitazione dei miti classici. Gianni RonDolino (Il cinema di Man Ray oltre Dada, pp.169-178) riflette sull'attività cinematografica di Man Ray che, a metà strada tra ricerca sperimentale e cinema d'ispirazione dadaista, si discosta dall'esperienza surrealista perché presenta un intento non casuale, né improvvisato. Secondo Giorgio tinAzzI (Cinema: l'occhio che rivela, pp. 179-187) l'ultima sequenza del film di Buñuel Cet obscur objet du désir è esemplare di quanto il cinema surrealista contribuisca a «allargare il visibile e trasformarlo» (p. 183). Se, da un lato, le scelte d'avanguardia (la dissociazione tra immagine e referente, il rifiuto dell'asse narrativo e l'inserzione di elementi casuali) trasgrediscono la norma, dall'altro, nel sancire l'indipendenza del cinema dal linguaggio teatrale e letterario, stabiliscono quindi un nuovo modello. 